\title{
Evaluation of pancreatic exocrine functions in rheumatoid arthritis
}

\author{
Sisman $\mathrm{P}^{1}$, Yucel $\mathrm{E}^{2}$ \\ Medicana Hospital, Endoscrinology and Metabolism Clinic, Bursa, Turkey. drpinarsisman@gmail.com
}

\begin{abstract}
BACKGROUND: Rheumatoid arthritis (RA) is one of the most common chronic inflammatory diseases. It mainly involves the joints and also affects directly or indirectly nearly all organ systems. The question whether RA causes exocrine pancreatic disfunction remains unclear. The purpose of this study is to evaluate whether or not RA contributes to pancreatic exocrine insufficiency. This was done by ruling out seconder Sjögren's syndrome (SjS) by using Schirmer's test.

METHODS: A total of 60 patients (20 RA, $20 \mathrm{RA}+\mathrm{SjS}$ and $20 \mathrm{SjS}$ ) and 20 healthy volunteers were included in the study. Patients with RA who had not undergonethe Schirmer's test in the last 6 months and all healthy volunteers included in the study underwent the Schirmer's test at an outpatient clinic. Random fecal samples were taken from all participants and fecal pancreatic elastase was measured to evaluate pancreatic exocrine functions. RESULTS: In the study, a statistically significant difference was found between the control group,SjS and RA+SjS groups. But there was no significant difference between the control group and RA group. In RA group, fecal elastase levels were statistically significantly higher compared to the SjS group. But there was no significant difference between RA+SjS and SjS groups.

CONCLUSION: Fecal elastase significantly decreased in SjS compared to the normal population while pancreatic exocrine functions are considered to be impaired in SjS. There are also impaired pancreatic exocrine functions in the secondary SjS associated with RA. Consequently, pancreatic exocrine dysfunction, which can be seen in patients with RA, may be thought to be caused by secondary SjS associated with RA (Tab. 6, Fig. 1, Ref. 19). Text in PDF www.elis.sk.

KEY WORDS: rheumatoid arthritis, fecal elastase, pancreatic exocrine function, Sjögren's syndrome.
\end{abstract}

\section{Introduction}

Although it is defined as a joint disease, RA has systemic manifestations. Extraarticular findings of RA are seen in 18-40 $\%$ of patients and are associated with worsened prognosis (1). The disease affects directly or indirectly nearly all organ systems, while causing a wide range of health issues from cardiovascular and respiratory problems to infections, depression and gastrointestinal ulcers (2). In an autopsy study conducted by Belly et al., acute pancreatitis was found in 6 out of 60 RA patients while chronic pancreatitis was found in 15 of them (3). In another study, the incidence of acute pancreatitis in RA patients was found in 185.7 per 100,000 person-years and excess risk of 1.62 compared with non-RA patients (2). However, Michaud et al. found that there was no evidence of increased rate of pancreatitis in RA (4).

The main histological feature is the lymphocytic infiltration of the salivary and ocular glands. Xerophthalmia is a major finding. The signs may be seen in various systems other than exo-

${ }^{1}$ Medicana Hospital, Endocrinology and Metabolism Clinic, Bursa, Turkey, and ${ }^{2}$ Baskent University, Medical School, Department of Rheumatology, Ankara, Turkey

Address for correspondence: P. Sisman, Medicana Hospital, Endoscrinology and Metabolism Clinic, Bursa, Turkey.

Phone: +532.1550811 crine glands, including skin, muscle, veins, joints, internal organs, blood and lymphatic system of $1 / 3$ of the patients $(5,6)$. Afzelius and colleagues observed in their study that $25 \%$ of the patients had morphological changes of the pancreas as evaluated by secretin-stimulated magnetic resonance cholangiopancreatography (MRCP), and two patients had chronic pancreatitis-like changes (7). In another study, the authors evaluated pancreatic functions by fecal elastase- 1 test in 50 chronic polyarthritis cases. They found that two cases ( $4 \%$; 95\% confidence interval, 1-14\%) had abnormally low fecal elastase level (8).

The main clinical finding of the exocrine pancreatic disorder is fat malabsorption. Patients suffer from weight loss, uncomfortable and bloating feeling in the abdomen. The diagnosis is based on clinical symptoms and assessment of direct and indirect tests (9). Indirect pancreatic function tests have lower sensitivity but higher applicability compared to direct tests. (10). The fecal elastase test is more sensitive and specifically reflects the pancreatic exocrine function, compared to other indirect tests although it does not achieve high specificity and sensitivity of direct function tests (11). Sensitivity and specificity of fecal elastase test were found to be $93 \%$ when cut-off value is accepted as $<200 \mu \mathrm{g} / \mathrm{g}(12)$. The purpose of this study is to evaluate whether or not RA contributes to pancreatic exocrine insufficiency. This is done by ruling out secondary SjS by using Schirmer's test. 


\section{Methods}

A total of 60 patients (20 RA, $20 \mathrm{RA}+\mathrm{SjS}$ and $20 \mathrm{SjS}$ ) and 20 healthy volunteers, who applied to our rheumatology outpatient clinic and met the criteria mentioned below were included in the study. Signed written consent was taken from the participants of the study, and the approval of the ethics committee of Başkent University was obtained. Inclusion criteria for RA patients: (i) patients younger than 60 years, (ii) duration of the disease $>1$ year, (iii) detection of Schirmer's test result $>15 \mathrm{~mm}$ or $\leq 5 \mathrm{~mm}$ in the last 6 months. Inclusion criteria for $\mathrm{SjS}$ patients: (i) patients younger than 60 years, (ii) duration of the disease $>1$ year. Inclusion criteria for control group: (i) patients younger than 60 years, (ii) Schirmer's test $>15 \mathrm{~mm}$, (iii) volunteers without systemic disease. Excluded from the study were conditions that affect pancreatic exocrine functions and Schirmer's test results, namely chronic pancreatitis, pancreatic cancers, pancreatic resections, gastrointestinal surgeries, diabetes mellitus, cystic fibrosis, amyloidosis, gluten enteropathy, periampullary tumors, Zollinger Ellison syndrome, Crohn's disease, short bowel syndrome, antidepressant, anticholinergic, neuroleptic, clonidine, diuretic use, granulomatous diseases (sarcoidosis, tuberculosis, leprosy), therapeutic radiation, head and neck trauma and surgery, dehydration, and patients over 60 years of age (except patients with $\mathrm{SjS}$ who were diagnosed with biopsy). The patients involved in the study were questioned about the duration of the illness, accompanying diseases, and the drugs they use. Abdominal ultrasonography was performed to evaluate the pancreatic morphology of the patients. The Schirmer's test was carried out in patients with RA who had not undergone it in the last 6 months and all control patients included in the study at the outpatient clinic. A 5-mm wide Whatman filter paper No 41 was placed inside the lateral third of the lower eyelid without anesthesia. The amount of moisture within the paper was measured after 5 minutes. If the moisture was ????? $\mathrm{mm}$ or less, the eye was considered "dry" (secondary $\mathrm{SjS}$ ); if it was more than $15 \mathrm{~mm}$, the result of Shirmer's test was considered normal. According to the Schirmer's test results, patients were divided into 2 groups. Patients with RA who were diagnosed as having the Schirmer's test $5 \mathrm{~mm}$ or less were accepted as $\mathrm{SjS}$ associated with RA (Group RA+ SjS).

Random fecal samples were taken from all participants and stored at $-20{ }^{\circ} \mathrm{C}$ until elastase measurement. Fecal pancreatic elastase was measured with a commercially avaliable ELISA test (Pancreatic Elastase ELISA; Bioserv Diagnostic GmbH, Rostock Germany), according to the manufacturer's instructions. Serum CRP levels were measured simultaneously with the fecal sample.

\section{Statistical analysis}

Baseline characteristics and fecal elastase results for all subjects and groups were given as mean ( \pm standard deviation), median (smallest-highest), or median (width between quarters) for appropriate variables after normal distribution tests of the data had been performed. The categorical variables are given as number (percentage). The Kruskal-Wallis variance analysis test was used for inferential statistics between the disease groups and control group, while Mann-Whitney-U test was used for the binary com- parison of drug use. Pearson / Spearman correlation coefficients were given in the correlation analysis with variables affecting the fecal elastase level. Multiple regression analysis was performed to examine the relationship of fecal elastase levels between groups independently of age. The SPSS program (Version 17, IBM SPSS Statistics, IBM Corporation, NY, USA) was used for calculations. $\mathrm{p}$ values $<0.05$ were considered statistically significant.

\section{Results}

The mean age of the patients included in the study was $49.2 \pm$ 7.9 years in the RA group, $52.3 \pm 6.6$ years in the $\mathrm{RA}+\mathrm{SjS}$ group, $51.0 \pm 11.3$ years in the $\mathrm{SjS}$ group, and $44.5 \pm 9.8$ years in the control group. There was a statistically significant difference between the mean ages of control group and RA group (Tab. 1). The duration of disease was $1.2(0-5)$ years in SJS group, $6(1-25)$ years in $\mathrm{RA}+\mathrm{SjS}$ group and 7 (1-25) years in RA group.

When fecal elastase values were compared according to sex, mean fecal elastase level in males was $643.0 \pm 134.4 \mu \mathrm{g} / \mathrm{g}$ and mean fecal elastase level in females was $666.1 \pm 234.6 \mu \mathrm{g} / \mathrm{g}$. It was observed that sex did not affect fecal elastase levels $(\mathrm{p}=0.799)$ (Tab. 2). When fecal elastase levels were measured in all groups, the median fecal elastase was $750.5 \mu \mathrm{g} / \mathrm{g}$ in the control group, $628.5 \mu \mathrm{g} / \mathrm{g}$ in $\mathrm{SjS}$ group, $577.5 \mathrm{ug} / \mathrm{g}$ in RA $+\mathrm{SjS}$ group, and 802.5 $\mu \mathrm{g} / \mathrm{g}$ in RA group. Statistically significant differences were found

Tab. 1. Evaluation of age and gender distribution by groups.

\begin{tabular}{lcc}
\hline Groups & $\begin{array}{c}\text { Age } \\
\text { mean } \pm \mathrm{SD}\end{array}$ & $\begin{array}{c}\text { Gender } \\
\mathrm{M} / \mathrm{F}\end{array}$ \\
\hline Control & $44.5 \pm 9.8^{\mathrm{c}}$ & $3 / 17$ \\
$\mathrm{SjS}$ & $51.0 \pm 11.3$ & $1 / 19$ \\
$\mathrm{RA}+\mathrm{SjS}$ & $52.3 \pm 6.6^{\mathrm{c}}$ & $3 / 17$ \\
RA & $49.2 \pm 7.9$ & $0 / 20$ \\
$\mathrm{p}$ & $0.044^{\mathrm{a}}$ & 0.126 \\
\hline
\end{tabular}

SD: Standart Deviation, M: Male, F: Female, a: One-Way ANOVA, b: Chi-square test, c: The difference between the control group and the RA+SjS group was statistically significant $(\mathrm{p}=0.039)$

Tab. 2. Evaluation of fecal elastase levels according to gender.

\begin{tabular}{lcc}
\hline Variables & $\begin{array}{c}\text { Fecal Elastase }(\mu \mathrm{g} / \mathrm{g}) \\
\text { mean } \pm \mathrm{SD}\end{array}$ & $\mathrm{p}$ \\
\hline Gender & & \\
Male $(\mathrm{n}=7)$ & $643.0 \pm 134.4$ & 0.799 \\
Female $(\mathrm{n}=73)$ & $666.1 \pm 234.6$ &
\end{tabular}

SD: Standard Deviation

Tab. 3. Evaluation of fecal elastase levels according to the groups.

\begin{tabular}{lc}
\hline Groups & $\begin{array}{c}\text { Fecal Elastase }(\mu \mathrm{g} / \mathrm{g}) \\
\text { median }(\mathrm{WBQ})\end{array}$ \\
\hline Control (n:20) & $750.5(88.5)^{\mathrm{b}, \mathrm{c}}$ \\
SjS (n:20) & $628.5(402.0)^{\mathrm{b}, \mathrm{d}}$ \\
RA+SjS (n:20) & $577.5(371.5)^{\mathrm{c}}$ \\
RA (n:20) & $802.5(433.7)^{\mathrm{d}}$ \\
$\mathrm{p}^{\mathrm{a}}$ & 0.034 \\
\hline
\end{tabular}

WBQ: Width Between Quartiles, a: Kruskal Wallis test, b: The difference between the control group and the $\mathrm{SjS}$ group was statistically significant $(\mathrm{p}=0.006), \mathrm{c}$ : The difference between the control group and the RA+SjS group was statistically significant ( $\mathrm{p}=0.037$ ), $\mathrm{d}$ : The difference between the $\mathrm{SjS}$ group and the RA group was statistically significant $(\mathrm{p}=0.013)$ 
Tab. 4. Examination of the effects of SjS, RA + SjS and RA groups according to the control group on the fecal elastase level when the age correction was performed.

\begin{tabular}{|c|c|c|c|c|}
\hline \multirow{2}{*}{ Variables } & \multirow{2}{*}{$\begin{array}{c}\text { Regression } \\
\text { Coefficient (B) }\end{array}$} & \multirow{2}{*}{$\mathrm{p}$} & \multicolumn{2}{|c|}{ 95\% Confidence Interval (B) } \\
\hline & & & Lower Limit & Upper Limit \\
\hline$\overline{\mathrm{SjS}}$ & -0.378 & 0.006 & -0.646 & -0.109 \\
\hline $\mathrm{RA}+\mathrm{SjS}$ & -0.261 & 0.059 & -0.533 & 0.011 \\
\hline RA & -0.088 & 0.511 & -0.352 & 0.177 \\
\hline Age & -0.003 & 0.558 & -0.013 & 0.007 \\
\hline
\end{tabular}

Tab. 5. Correlation coefficient and significance levels between age, duration of disease and CRP, fecal elastase.

\begin{tabular}{lcc}
\hline Variables & $\mathrm{R}$ & $\mathrm{p}$ \\
\hline Age & -0.146 & 0.195 \\
Duration of disease & 0.093 & 0.479 \\
CRP & -0.167 & 0.139 \\
\hline
\end{tabular}

Tab. 6. Evaluation of fecal elastase levels according to drugs.

\begin{tabular}{|c|c|c|}
\hline Variables & $\begin{array}{c}\text { Fecal Elastase }(\mu \mathrm{g} / \mathrm{g}) \\
\text { Mean } \pm \mathrm{ss}\end{array}$ & $\mathrm{p}$ \\
\hline $\begin{array}{l}\text { NSAID } \\
\text { positive }(\mathrm{n}=38) \\
\text { negative }(\mathrm{n}=22) \\
\end{array}$ & $\begin{array}{l}617.7 \pm 238.3 \\
658.1 \pm 259.0 \\
\end{array}$ & 0.542 \\
\hline $\begin{array}{l}\text { CORTICOSTEROIDS } \\
\text { positive }(\mathrm{n}=43) \\
\text { negative }(\mathrm{n}=17) \\
\end{array}$ & $\begin{array}{l}600.9 \pm 237.3 \\
712.5 \pm 252.1 \\
\end{array}$ & 0.112 \\
\hline $\begin{array}{l}\text { PPI } \\
\text { positive }(\mathrm{n}=33) \\
\text { negative }(\mathrm{n}=27) \\
\end{array}$ & $\begin{array}{l}634.4 \pm 217.2 \\
630.3 \pm 279.0 \\
\end{array}$ & 0.948 \\
\hline $\begin{array}{l}\text { HCQ } \\
\text { positive }(\mathrm{n}=16) \\
\text { negative }(\mathrm{n}=44)\end{array}$ & $\begin{array}{l}582.4 \pm 183.0 \\
650.8 \pm 263.1 \\
\end{array}$ & 0.266 \\
\hline $\begin{array}{l}\text { MTX } \\
\text { positive }(n=36) \\
\text { negative }(n=24) \\
\end{array}$ & $\begin{array}{l}621.6 \pm 233.6 \\
649.0 \pm 264.8 \\
\end{array}$ & 0.674 \\
\hline $\begin{array}{l}\text { SLZ } \\
\text { positive }(n=46) \\
\text { negative }(n=14)\end{array}$ & $\begin{array}{l}607.0 \pm 232.1 \\
716.4 \pm 274.6\end{array}$ & 0.145 \\
\hline $\begin{array}{l}\text { LEFLUNOMID } \\
\text { positive }(n=54) \\
\text { negative }(n=6)\end{array}$ & $\begin{array}{l}633.0 \pm 253.2 \\
628.2 \pm 164.5 \\
\end{array}$ & 0.964 \\
\hline
\end{tabular}

NSAID: Nonsteroid anti-inflammatory drugs, PPI: Proton pump inhibitors, HCQ: Hydroxychloroquine, MTX: Methotrexate, SLZ: Sulfasalazine

between the control group and $\mathrm{SjS}$ group $(\mathrm{p}=0.006)$ as well as between the control group and RA $+\operatorname{SjS}$ group $(p=0.037)$. In the RA group, fecal elastase levels were statistically higher than in $\mathrm{SjS}$ group $(\mathrm{p}=0.013)$. The difference between $\mathrm{RA}+\mathrm{SjS}$ and RA groups was not statistically significant $(p=0.07)($ Tab. 3).

When adjusted for age, it was observed that the level of fecal elastase in the $\mathrm{SjS}$ group was lower compared to the control group $(p=0.006)$. When adjusted for age, the level of fecal elastase in the $\mathrm{RA}+\mathrm{SjS}$ group was not statistically significant $(\mathrm{p}=0.059)$. The similarity between the control group and RA group was also observed when age-adjusted correction was made $(p=0.558)($ Tab. 4).

There was no significant correlation between age and fecal elastase levels in our study $(r=-0.146 ; p=0.195)$. There was no significant correlation between disease duration and fecal elastase level $(r=0.093 ; p=0.479)$. There was no significant correlation between CRP and fecal elastase levels $(r=-0.167 ; p=0.139)$. The results are given in Table 5 .

\section{Discussion}

RA is one of the most common chronic inflammatory diseases. Although the disease mainly involves the joints, it also causes extraarticular manifestations (13). SjS is a chronic inflammatory autoimmune disease that predominantly involves exocrine glands. It can occur in conjunction with other autoimmune disorders and RA is the most common connective tissue disease associated with $\mathrm{SjS}$ (14).

Studies investigating pancreatic exocrine dysfunction have been performed on patients with $\mathrm{SjS}$ mostly in rheumatology. In a study conducted by Sumii T. et al., pancreatic exocrine functions (reduction in bicarbonate secretion) were investigated by performing a secretin stimulation test in patients with $\mathrm{SjS}$ (15). In this study, it was concluded that the decrease in bicarbonate secretion was characteristic. In another study conducted by Candellli and his colleagues, pancreatic exocrine functions were assessed by fecal chymotrypsin test and it was found that in patients with $\mathrm{SjS}$, exocrine functions were statistically significantly lower than in the control group. It was also found that this was parallel to Schirmer test results (16). In this study, in the group of patients with $\mathrm{SjS}$, the mean elastase level was $562.50 \mu \mathrm{g} / \mathrm{g}$, and there was a statistically significant difference compared to control group. This result has been evaluated as $\mathrm{SjS}$ that affects pancreatic exocrine functions.

In the literature, there are also studies on pancreas functions and relationship with disease duration in $\mathrm{SjS}$. In a study, PABA test, serum immunoreactivity trypsin levels and fecal fat measurement tests were performed in primary and secondary $\mathrm{SjS}$ and it was found that pancreatic dysfunction is more severe in long-term disease (17). In another study, serum immunoreactive trypsin levels were found to be higher in primary SJS compared to secondary SjS, and the disorder was more frequent in cases with disease duration over 10 years. However, there was no clinical pancreatitis in any of pancreatic exocrine dysfunction cases. (18). In our study, no

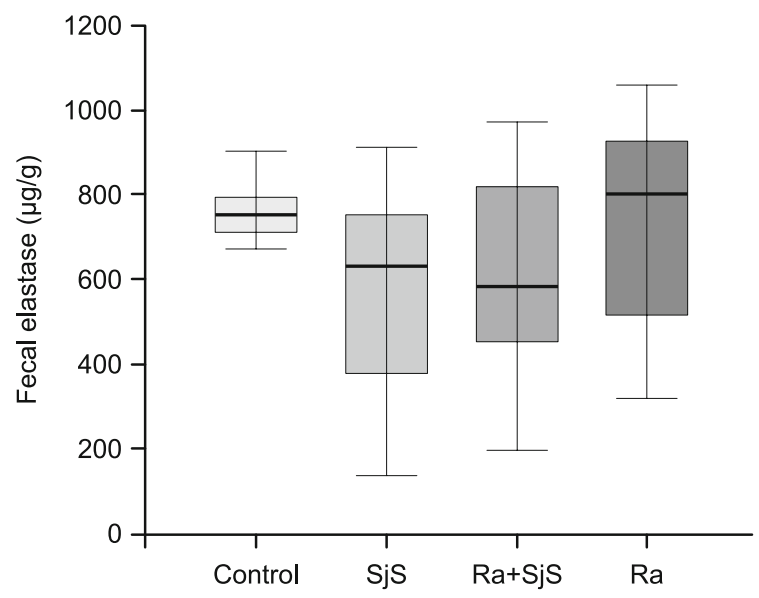

Fig. 1. Fecal elastase levels according to the groups. 
statistically significant relationship was found between the duration of disease and pancreatic functions $(p=0.479)$. There was no clinical pancreatitis in our patients either.

There are also studies in the literature investigating the effect of RA on pancreatic exocrine functions. In a study conducted by Gobelet et al, pancreatic exocrine functions were investigated by PABA test which was abnormal in $37.5 \%$ of $\mathrm{SjS}$ and $35 \%$ of RA, with no abnormalities in the control group (19). In our study, no statistically significant difference was found between the control group and RA group in which the secondary $\mathrm{SjS}$ was excluded $(p=0.776)$.

In our study, mean fecal elastase levels of patients were 666.1 $\pm 234.6 \mu \mathrm{g} / \mathrm{g}$ in women and $643.0 \pm 134.4 \mu \mathrm{g} / \mathrm{g}$ in men. There was no statistical difference in mean fecal elastase levels between women and men $(p=0.799)$. There was no statistically significant correlation between fecal elastase and age $(p=0.195)$ either. There was no statistically significant relationship between pancreatic exocrine function and drugs used by the patients, e.g. methotrexate, sulfasalazine, hydroxychloroquine, leflunomide, corticosteroids, proton pump inhibitors, nonsteroidal antiinflammatory drugs. There was no significant association between pancreatic exocrine functions and CRP levels in our study.

The best cut-off value for fecal elastase level was determined to be $200 \mu \mathrm{g} / \mathrm{g}$. The fecal elastase results of $2(2.5 \%)$ of the patients in our study were found to be below $200 \mu \mathrm{g} / \mathrm{g}$. It is known that fecal elastase is a sensitive test for detecting moderate and severe pancreatic insufficiency. Therefore, it can be assumed that other patients might have slightly exogenous pancreatic exocrine dysfunction or that fecal elastase 1 levels might have a different cut-off value for autoimmune diseases. Controlled studies involving a larger number of patients with long-term follow-up are necessary to be able to conclude in this decision.

In our study, fecal elastase levels in $\mathrm{SjS}$ and $\mathrm{RA}+\mathrm{SjS}$ groups were statistically significantly lower than those of the control group. Fecal elastase levels in the RA group and control group were similar. In accordance with literature, these results have also shown that pancreatic exocrine functions were impaired in $\mathrm{SjS}$. Pancreatic exocrine function was also impaired in the secondary $\mathrm{SjS}$ associated with RA. But there was no pancreatic exocrine dysfunction in patients with RA without concommitant secondary $\mathrm{SjS}$. These results suggest that impaired pancreatic exocrine function in RA patients may be caused by secondary $\mathrm{SjS}$ associated with RA. However, for better understanding of the pancreatic exocrine dysfunctions seen in RA, long-term and controlled studies involving a larger number of patients are necessary.

\section{References}

1. Alunno A, Gerli R, Giacomelli R, Carubbi F. Clinical, epidemiologicaland histopathological features of respiratory involvement in rheumatoid arthritis. Biomed Res Int 2017; 2017: 7915340. doi: 10.1155/2017/7915340.

2. Chang CC, Chiou CS, Lin HL, Wang LH, Chang YS, Lin HC. Increased risk of acute pancreatitis in patient with rheumatoid arthritis: A population-based cohort study. PLoS One 2015; 10 (8): e0135187. doi: 10.1371/journal.pone.0135187.
3. Bely M, Apathy A, Pinter T, Ratko I. Pancreatitis in rheumatoid arthritis found in autopsy material. Morphol Igazsagugyi Orv Sz 1989; 29: 213-221.

4. Michaud K, Wolfe F. Comorbidities in rheumatoid arthritis. Best Pract Res Clin Rheumatol 2007; 21 (5): 885-906.

5. Locht H, Pelck R, Manthorpe R. Clinical manifestations correlated to the prevelance of autoantibodies in a large $(n=321)$ cohort of patients with primary Sjögren's syndrome Acomparison of patients initially diagnosed according to the Copenhagen classification cirteria with the American-European consensus cirteria. Autoimmun Rev 2005; 4: 276-281.

6. Rhodus NL, Bloomquist C, Liljemark W, Bereuter J. Prevelance, density and manifestations of oral Candida Albicans in patients with Sjögren's syndrome. J Otolaryngol 1997; 26: 300-305.

7. Afzelius P, Fallentin EM, Larsen S, Møller S, Schiødt M. Pancreatic function and morphology in Sjögren's syndrome. Scand J Gastroenterol 2010; 45 (6): 752-758.

8. Kauppi M, Kankaanpää E, Kautiainen H. Exocrine disfunction of the pancreas in patients with chronic polyarthritis. J Clin Rheumatol 2001; 7 (3): 166-169.

9. Gullo L. Direct pancreatic function test (duodenal intubation) in the diagnosis of chronic pacreatitis. Gastroenterology 1986; 90: 799-800.

10. Sisman P, Avci M, Akkurt A, Sahin AB, Gul OO, Ersoy C, Erturk E. The effect of primary hyperparathyroidism on pancreatic exocrine function. J Endocrinol Invest 2017 Aug 2. doi: 10.1007/s40618-017-0727-6.

11. Naruse S, Ishiguro H, Ko SBH, Yoshikawa T, Yamamoto T, Yamamoto A, Futakuchi S, Goto H, Saito Y, Takahashi S. Fecal pancreatic elastase: a reproducible marker for severe exocrine pancreatic insufficiency. J Gastroenterol 2006; 41: 901-908.

12. Dominici R, Franzini C. Fecal elastase-1 as test of pancreatic function: a review. Clin Chem Lab Med 2002; 40 (4): 325-32.

13. Lin HC, Xirasagar S, Lee CZ, Huang CC, Chen CH. The association between gastro-oesophageal reflux disease and subsequent rheumatoid arthritis occurrence: a nested case-control study from Taiwan. BMJ Open 2017; 7: e016667. doi: 10.1136/bmjopen-2017-016667.

14. Hajiabbasi A, Shenavar Masooleh I, Alizadeh Y, Banikarimi AS, Ghavidel Parsa P. Secondary Sjogren's Syndrome in 83 Patients With Rheumatoid Arthritis. Acta Med Iran 2016; 54 (7): 448-453.

15. Sumii T, Ando B, Sakai K. Chronic pancreatitis and pancreatic dysfunction associated with Sjogren's syndrome. Nippon Rinsho Oct 1995; 53 (10): 2525-2529.

16. Candelli M, Manganelli C, Nista EC, Armuzzi A, Danase S, Ojetti $\mathbf{V}$, et al. Evaluation of exocrine pancreatic involvement in primitive Sjogren's syndrome by Mixed Triglyceride Breath Test and fecal chymotrypsin and its relation with Schirmer's test. Internal Medicine and Ophtalmology depts. Catholic University of Rome, Italy.

17. Coll J, Navarro S, Tomas R, Elena M, Martinez E. Exocrine pancreatic function in Sjogren's Syndrome. Arch Intern Med 1989; 149 (4): $848-852$.

18. Pal B, Griffiths ID, Katrak A, Junglee D, Dandona P. Salivary Amylase and Pancreatic Enzymes in Sjogren's Syndrome. Clin Chem 1987; 33 (2): 305-307.

19. Gobelet C, Gerster JC, Pappoport G, Hiroz CA, Maeder E. A controlled study of the exocrine pancreatic function in Sjogren's syndrome and rheumatoid arthritis. Clin Rheumatol Jun 1983; 2 (2): 139-143.

Received March 2, 2018. Accepted April 3, 2018. 